Letter to the Editor

\title{
Central retinal artery occlusion showing features of paracentral acute middle maculopathy following uncomplicated pterygium surgery
}

Roderick O'Day MBBS, ${ }^{1}$ C Alex Harper FRANZCO ${ }^{1,2}$ and Sanjeewa S Wickremasinghe DMedSc FRANZCO ${ }^{1,2}$

${ }^{1}$ Medical Retina Unit, Royal Victorian Eye and Ear Hospital, 32 Gisborne Street, East Melbourne, Vic 3002, Australia

${ }^{2}$ Centre for Eye Research Australia, University of Melbourne, Melbourne, Vic 3002, Australia

Correspondence: Roderick O’Day, Royal Victorian Eye and Ear Hospital, 32 Gisborne Street, East Melbourne, Vic 3002, Australia

Email: roderick.oday@gmail.com

Received 22 April 2018; accepted 25 June 2018

Conflict of interest: None

Funding sources: None

This is the author manuscript accepted for publication and has undergone full peer review but has not been through the copyediting, typesetting, pagination and proofreading process, which may lead to differences between this version and the Version of Record. Please cite this article as doi: 10.1111/ceo.13353

This article is protected by copyright. All rights reserved. 
Perioperative inner retinal infarction is a devastating cause of irreversible central visual loss.(1) The clinical presentations of this range from manifest features of central retinal artery occlusion (CRAO) through to a spectral-domain optical coherence tomography (SD-OCT) finding of subtle paracentral acute middle maculopathy (PAMM) with a normal fundus appearance. $(1,2)$ The pathogenesis of the inner retinal infarction is unclear. It has most commonly been encountered following intraocular surgery, suggesting that the intraocular environment during a procedure may be an important potential causative factor. We report a case of CRAO with associated PAMM following extraocular surgery with peribulbar anaesthesia.

A 73-year-old male underwent routine nasal pterygium excision and conjunctival autograft with additional biopsy of an area of conjunctivalisation of the temporal cornea in his left eye. His past medical history was unremarkable, specifically with no history of cardiovascular disease and he was a non-smoker. Preoperatively, his best-corrected visual acuity (BCVA) was 6/6 in the right eye and 6/9 in the left eye. An inferotemporal peribulbar injection of local anaesthetic consisting of $3 \mathrm{ml}$ of a mixture of lignocaine $2 \%$, ropivicaine $0.8 \%$ and hyaluronidase 30 units / $\mathrm{ml}$ was performed. External compression was applied manually. Sedation consisting of 500 micrograms of alfentanil was used prior to the local anaesthetic block. The patient was mildly hypertensive during the procedure, with blood pressure (BP) of approximately 160/80 throughout, but he remained normocardic. The surgery was uncomplicated. The patient had poor vision in the operated eye on removing the eye pad the next morning. BCVA was counting fingers (CF) and his intraocular pressure was $22 \mathrm{~mm} / \mathrm{Hg}$. The anterior segment had a normal postoperative appearance. Posterior segment examination revealed retinal pallor and oedema throughout the macula with a cherry red spot at the fovea (Figure 1). There was no evidence of emboli at the optic nerve head or within the retinal vasculature. SD-OCT showed retinal thickening and hyper-reflectivity of the middle retinal layers with sparing of 
the outer retina. (Figure 2A) A provisional diagnosis of CRAO with associated PAMM was made. Investigations were performed to rule out an embolic or inflammatory cause. Serum inflammatory markers, carotid doppler ultrasound scanning, electrocardiography, transthoracic echocardiography and computed tomography of the brain were all reported as normal. The patient was found to be consistently hypertensive at follow up appointments, but workup up for other cardiovascular disease was unremarkable.

Twelve weeks after surgery, BCVA was CF in the affected eye and a relative afferent pupillary defect was present, but there was no disc pallor. SD-OCT showed inner retinal thinning and disorganisation, but preservation of the outer retinal structures. (Figure 2B)

CRAO has been reported following ocular surgery with retrobulbar, peribulbar and sub-tenon's anaesthesia. $(1,3,4)$ Most commonly it has been reported following intraocular surgery, but does occur following extraocular surgery, including pterygium surgery.(4) PAMM is an SD-OCT finding that is thought to represent ischaemia of the intermediate and deep retinal capillary plexus.(2) In the acute phase of PAMM there are band-like lesions consisting of swelling and hyperreflectivity of the middle retina, which, over time regress leaving an atrophic inner nuclear layer.(2) It has been described in a wide range of retinal vascular and extrinsic disorders.(5)

In the peri-operative setting, it has been proposed that inner retinal infarction is caused by retinal artery hypo-perfusion with clinical features ranging from a normal fundus appearance with subtle PAMM lesions on SD-OCT through to full-blown CRAO as was present in our case.(1) The pathogenesis of the retinal artery hypo-perfusion in this syndrome is not clear. Intraocular use of adrenaline and high intraocular 
pressure during a procedure have been proposed as potential contributing factors. This case highlights that these can not be the only causative factors. Potential mechanisms for a local anaesthetic block to cause retinal artery hypo-perfusion include vasospasm secondary to the medications used in the block and localised high orbital pressure either due to injected fluid or external pressure applied after the block is performed.

The risk factors for developing CRAO with associated PAMM following ocular surgery are not known due to its rarity. This patient, however, would have been considered low risk: the block used was low volume, did not include adrenaline and the patient had no known cardiovascular risk factors.(1) It is, accordingly, difficult to implement strategies to prevent it in the future. Anecdotally, CRAO with associated PAMM following ocular surgery has not been reported following a procedure using topical anaesthesia and accordingly could reduce the risk of future occurrence.

Our case highlights a newly described clinical entity of CRAO with associated PAMM following extraocular surgery. Further research is necessary to better understand the pathogenesis of this devastating complication.

\section{REFERENCES}

1. Creese K, Ong D, Sandhu SS, Ware D, Alex Harper C, Al-Qureshi SH, et al. Paracentral acute middle maculopathy as a finding in patients with severe vision loss following phacoemulsification cataract surgery. Clin Experiment Ophthalmol. 2017; 45: 598-605.

2. Rahimy E, Sarraf D. Paracentral acute middle maculopathy spectral-domain optical coherence tomography feature of deep capillary ischemia. Curr Opin Ophthalmol. 2014; 25: 207-12. 
3. Feibel RM, Guyton DL. Transient central retinal artery occlusion after posterior sub-Tenon's anesthesia. J Cataract Refract Surg. 2003; 29: 1821-4.

4. Calenda E, Rey N, Marguerite C, Muraine M. Central retinal artery occlusion after peribulbar anesthesia: report of 3 cases. Acta Anaesthesiol Belg. 2009; 60: 47-50.

5. Rahimy E, Kuehlewein L, Sadda SR, Sarraf D. Paracentral Acute Middle Maculopathy: What We Knew Then and What We Know Now. Retina Phila Pa. 2015; 35: 1921-30. 


\section{FIGURE LEGENDS}

Figure 1: Colour photo of the left eye one day following pterygium excision and conjunctival autograft.

Figure 2: Spectral domain optical coherence tomography of the left eye at day one (A) and at 12 weeks (B) post pterygium excision and conjunctival autograft. 

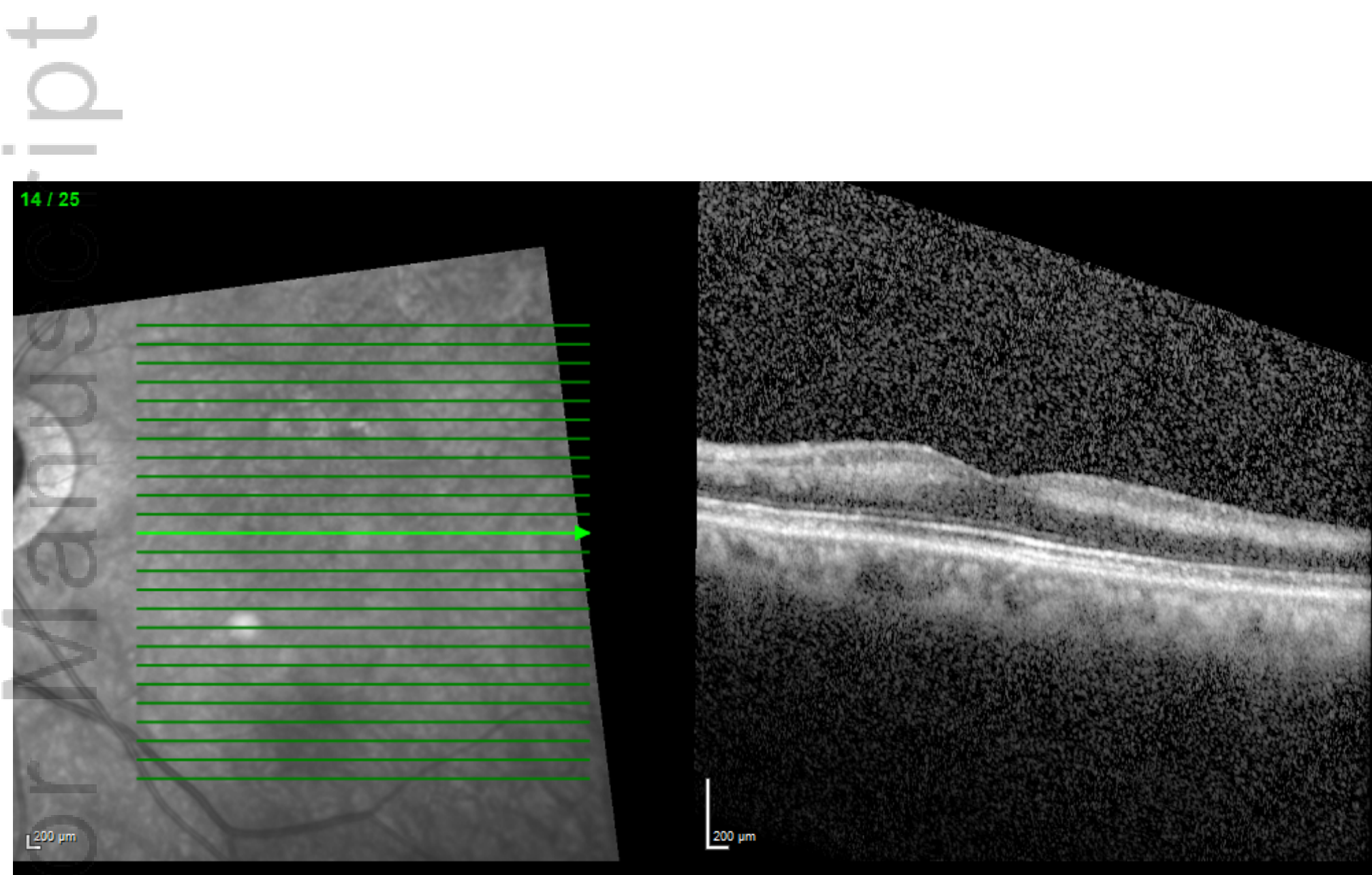

$30 / 01 / 2018$, OS

IR\&OCT $30^{\circ}$ ART [HS] ART(9) Q: 20

Figure_2B.tif 


\section{University Library}

\section{- M M N E R VA A gateway to Melbourne's research publications}

Minerva Access is the Institutional Repository of The University of Melbourne

\section{Author/s:}

O'Day, R;Harper, CA;Wickremasinghe, SS

Title:

Central retinal artery occlusion showing features of paracentral acute middle maculopathy following uncomplicated pterygium surgery

\section{Date:}

2019-01-01

\section{Citation:}

O'Day, R., Harper, C. A. \& Wickremasinghe, S. S. (2019). Central retinal artery occlusion showing features of paracentral acute middle maculopathy following uncomplicated pterygium surgery. CLINICAL AND EXPERIMENTAL OPHTHALMOLOGY, 47 (1), pp.141-143. https://doi.org/10.1111/ceo.13353.

Persistent Link:

http://hdl.handle.net/11343/284163 